\title{
A New Mechanism Towards Understanding the Origin of DNA Oxidation Biomarkers Under Hypoxia Condition - a Theoretical Perspective
}

\author{
Shuang Zhao ${ }^{1}$, Shan Jiang ${ }^{1}$, Min Wang $^{1}$, Chunyan Cao ${ }^{1}$, and Xin Wan ${ }^{1}$ \\ ${ }^{1}$ Bohai University
}

June 19, 2020

\begin{abstract}
Reactivity of thymine peroxy radical in DNA and its fate under hypoxia or oxygen-less conditions are studied at the M06-2X/6$31+\mathrm{G}(\mathrm{d}, \mathrm{p})$ level. The spaciously most accessible H2' can be abstracted by C6-peroxy radical in an intranucleotidyl manner with the estimated barriers of $18.8 \sim 21.1 \mathrm{kcal} / \mathrm{mol}$. The calculations show that C6-peroxy radical has a highly more reactivity towards $\mathrm{C}(\mathrm{sp} 3)-\mathrm{H}$ abstraction reactions than its relative C6-yl, which is a counter-intuitive case. The formed hydroperoxide with the $\mathrm{C} 6-\mathrm{OaObH} 2$ ' constituent can fast transfer $\mathrm{ObH} 2$ ' group to $\mathrm{C} 2$ ' radical in an intranucleotidyl manner with a low barrier (ca. $13.2 \mathrm{kcal} / \mathrm{mol}$ ) and very strong heat release. The results show that the formed hydroperoxide product is unstable so that it could be quickly transformed into other species and thus is very hard to be experimentally observed. Afterwards, H2' can be again abstracted by C6-oxyl radical to result in formation of thymine glycol which is the main products. The parallel C5-C6 bond scission reaction leads to formation of the precursor for 5-hydroxy-5-methylhydantion. The two competitive reactions have very low barriers. Based on our present calculations, the new radical reaction paths to formation of the DNA oxidation products are suggested under hypoxia or oxygen-less conditions, which is different from the previously suggested paths under high oxygen concentration surroundings.
\end{abstract}

\section{Hosted file}

Manuscript.doc available at https://authorea.com/users/334967/articles/460911-a-newmechanism-towards-understanding-the-origin-of-dna-oxidation-biomarkers-under-hypoxiacondition-a-theoretical-perspective 


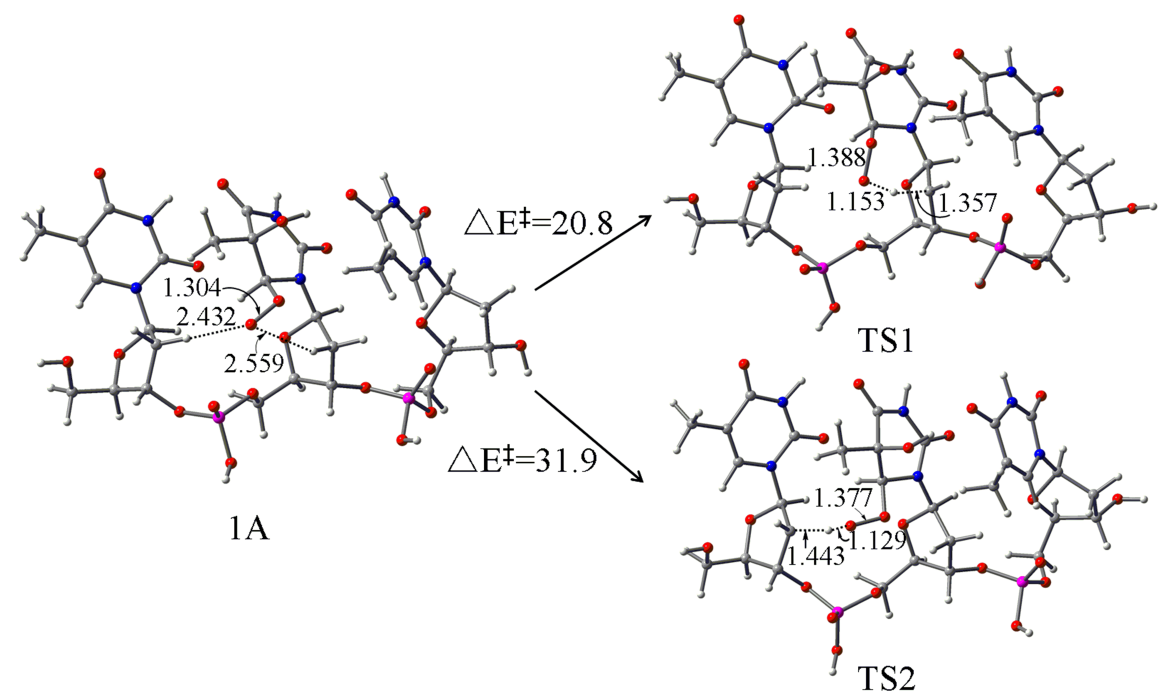

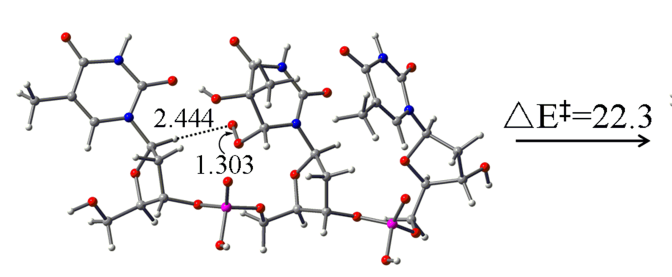

$1 A^{\prime}$

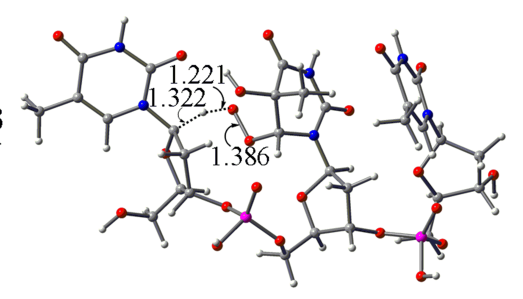

TS3

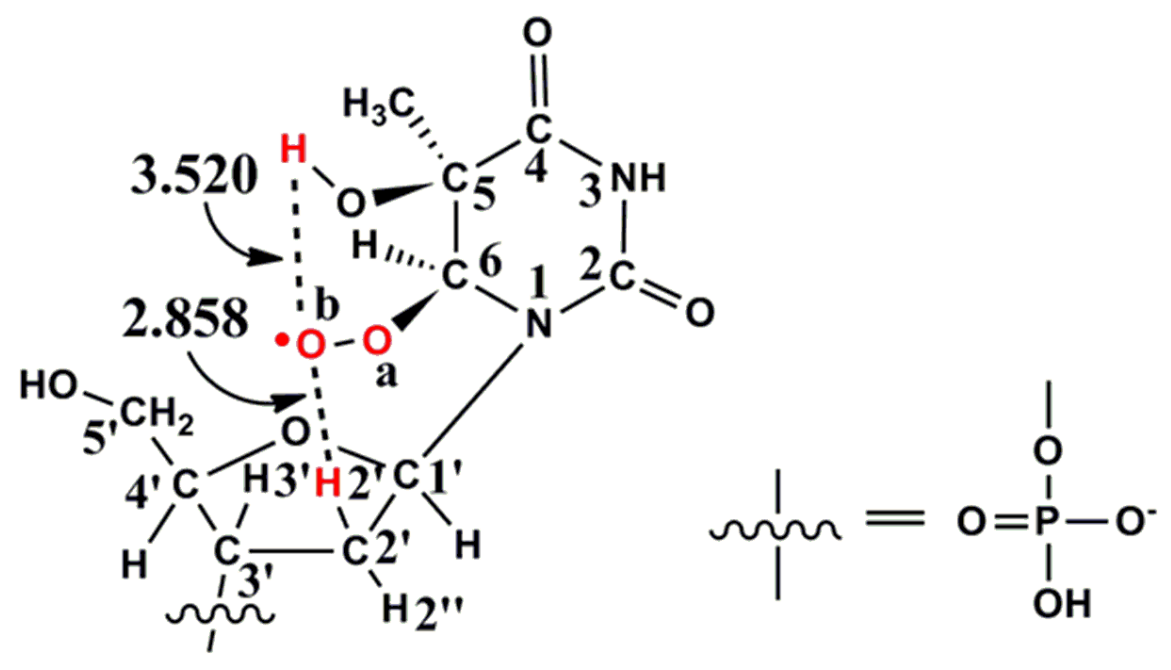

B 

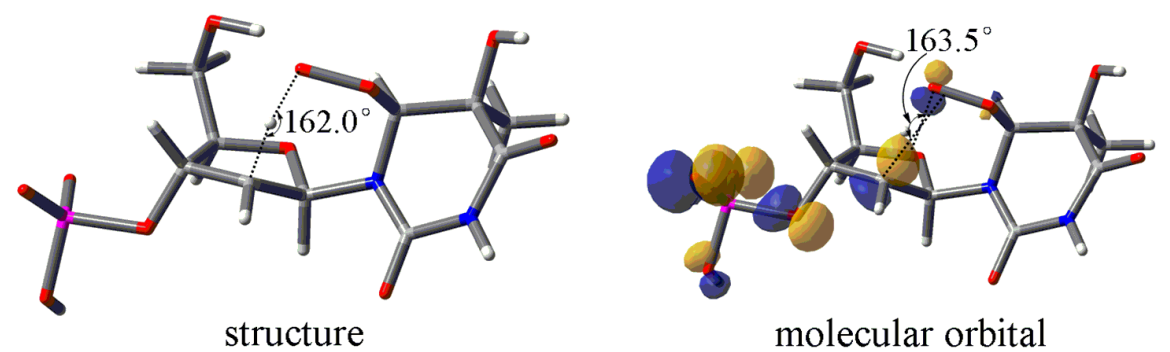

(a) The transition state of $\mathrm{H} 2$ ' abstraction by C6-peroxy radical

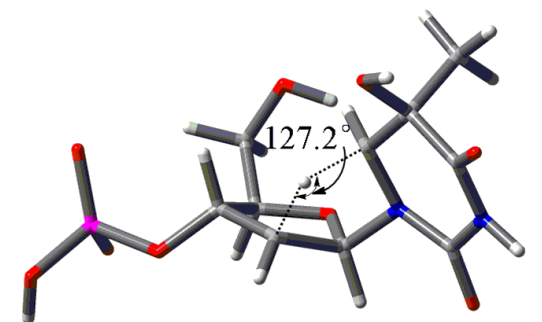

structure

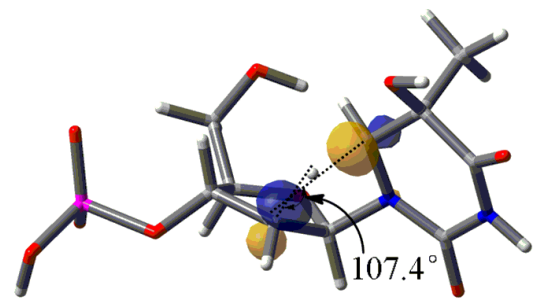

molecular orbital

(b) The transition state of $\mathrm{H}_{2}$ ' abstraction by $\mathrm{C} 6-\mathrm{yl}$ radical

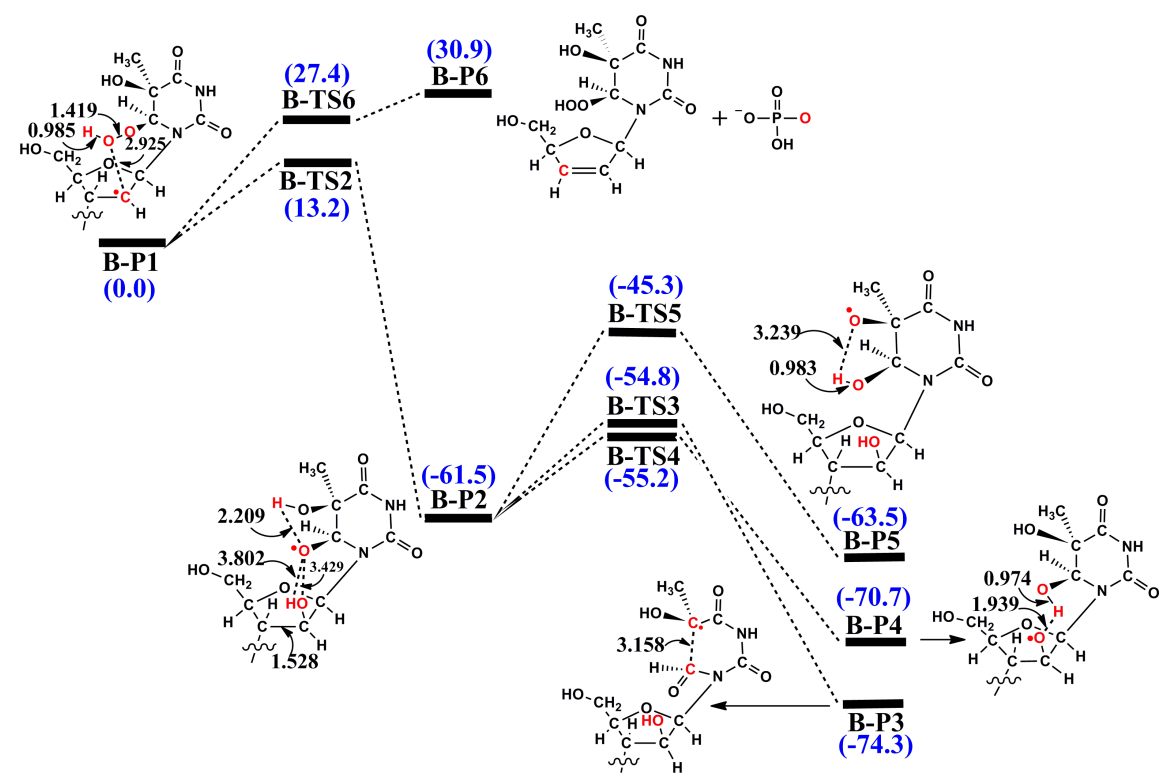




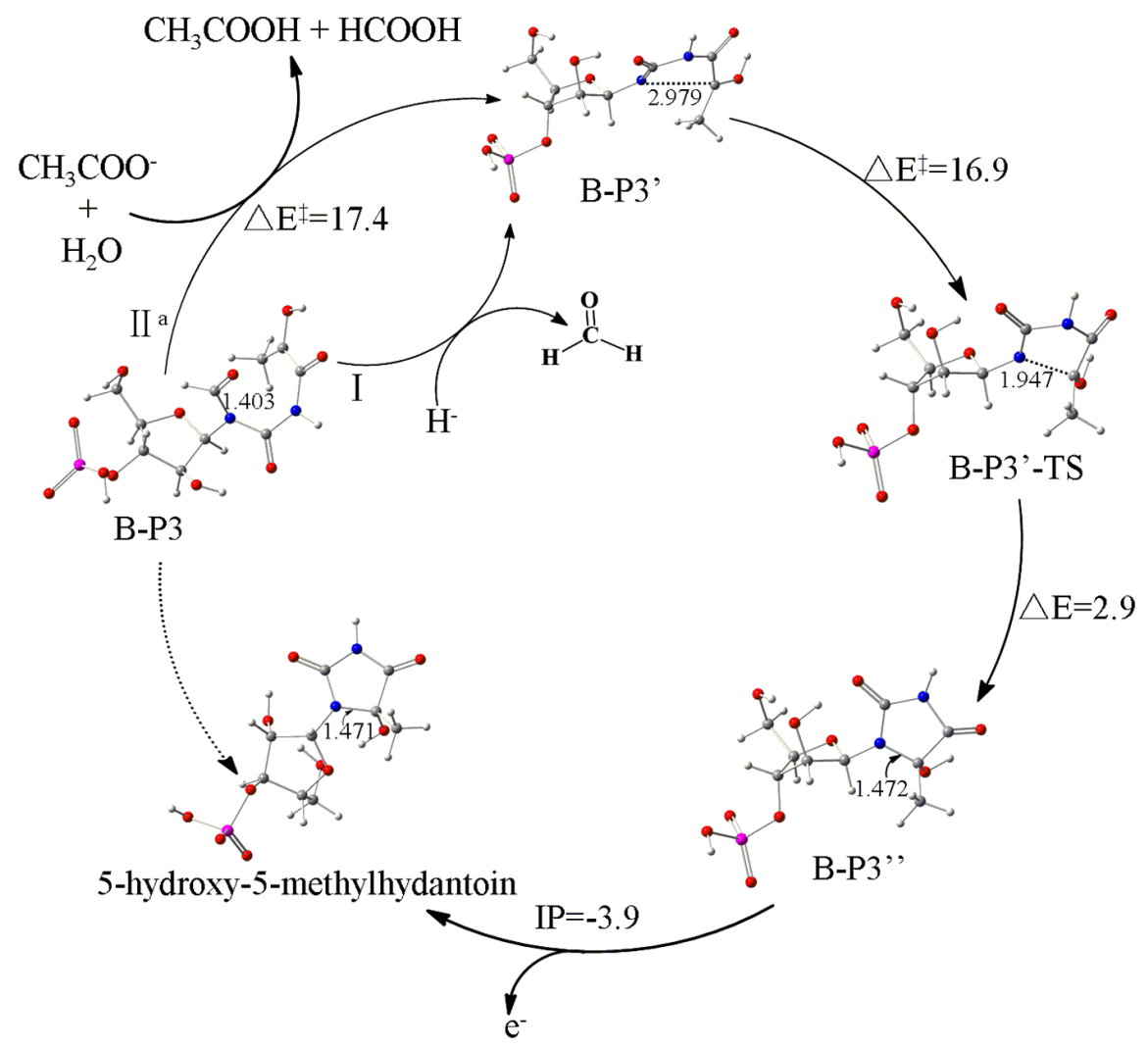

\section{Hosted file}

Tables.docx available at https://authorea.com/users/334967/articles/460911-a-new-mechanismtowards-understanding-the-origin-of-dna-oxidation-biomarkers-under-hypoxia-condition-atheoretical-perspective 